OPEN ACCESS

Edited by:

Liwu Li,

Virginia Tech, United States

Reviewed by:

Inger Øynebråten

Oslo University Hospital, Norway

Keehoon Jung,

Seoul National University, South Korea

*Correspondence:

Francesco Acquati

francesco.acquati@uninsubria.it

Specialty section:

This article was submitted to

Molecular Innate Immunity,

a section of the journal

Frontiers in Immunology

Received: 20 August 2019 Accepted: 18 October 2019

Published: 05 November 2019

Citation:

Acquati F, Mortara L, De Vito A,

Baci D, Albini A, Cippitelli M,

Taramelli $R$ and Noonan DM (2019)

Innate Immune Response Regulation

by the Human RNASET2 Tumor

Suppressor Gene.

Front. Immunol. 10:2587.

doi: 10.3389/fimmu.2019.02587

\section{Innate Immune Response Regulation by the Human RNASET2 Tumor Suppressor Gene}

\author{
Francesco Acquati ${ }^{1 *}$, Lorenzo Mortara ${ }^{2}$, Annarosaria De Vito ${ }^{1}$, Denisa Baci ${ }^{2}$, \\ Adriana Albini ${ }^{3,4}$, Marco Cippitelli ${ }^{5}$, Roberto Taramelli ${ }^{1}$ and Douglas M. Noonan ${ }^{2,4}$ \\ ${ }^{1}$ Human Genetics Laboratory, Department of Biotechnology and Molecular Sciences, University of Insubria, Varese, Italy, \\ ${ }^{2}$ Immunology and General Pathology Laboratory, Department of Biotechnology and Life Sciences, University of Insubria, \\ Varese, Italy, ${ }^{3}$ School of Medicine and Surgery, University of Milano-Bicocca, Monza, Italy, ${ }^{4}$ Scientific and Technology Pole, \\ IRCCS MultiMedica, Milan, Italy, ${ }^{5}$ Department of Molecular Medicine, Faculty of Pharmacy and Medicine, University La \\ Sapienza, Rome, Italy
}

The link between cancer development or progression and immune system dysregulation has long been established. Virtually every cell type belonging to both the innate and adaptive immune system has been reported to be involved in a complex interplay that might culminate into either a pro- or anti-tumorigenic response. Among the cellular components of the innate immune system, cells belonging to the monocyte/macrophage lineage have been consistently shown to play a key role in the tumorigenic process. The most advanced human tumors are reported to be strongly infiltrated with Tumor-Associated Macrophages (TAMs) endowed with the ability to contribute to tumor growth and dissemination. However, given their widely acknowledged functional plasticity, macrophages can display anti-tumor properties as well. Based on these premises, experimental approaches to promote the in vivo macrophage shift from pro-tumor to anti-tumor phenotype represent one of the most promising research field aimed at developing immune system-mediated tumor suppressive therapies. In this context, the human RNASET2 oncosuppressor gene has emerged as a potential tool for macrophage-mediated tumor suppression. A growing body of experimental evidence has been reported to suggest a role for this gene in the regulation of macrophage activity in both in vitro and in vivo experimental models. Moreover, several recent reports suggest a role for this gene in a broad range of cell types involved in immune response, pointing at RNASET2 as a putative regulator of several functional features within the immune system.

Keywords: T2 RNases, innate immune response, tumor suppression, stress response, tumor microenvironment, targeting immunotherapy

\section{INTRODUCTION}

The innate immune system represents an evolutionary conserved host defense tool, with many key features being shared between plants, invertebrates, and vertebrates (1).

However, dysfunction of this defense system is also involved in a wide range of pathologies, which include cancer and autoimmune disease in humans $(2,3)$.

In cancer, key cellular components of the innate immune system undergo a significant alteration in their effector functions, whose final result is the expression of tolerant or pro-tumor 
functions (4). By contrast, autoimmune diseases are usually associated with an abnormal, excessive response of $\mathrm{CD}^{+} \mathrm{T}$ helper (Th) cell subsets in cooperation with myeloid innate immune cells $(5,6)$. Despite recent significant progresses have been achieved in understanding cancer biology, the diagnosis and treatment of cancer still represent one the leading cause of death in western countries, whereas autoimmune diseases still strike millions of people worldwide. In cancer, tumor cells make themselves invisible to the adaptive immune system, by up-regulating self-defense mechanisms which promote immunological self-tolerance (7). The discovery of immune check-point molecules that limit autoimmunity, and their blockade in cancer treatment, has been recently exploited as an anti-cancer therapeutic approach $(8,9)$.

Among the cellular components of the innate immune system, macrophages represent key effector cells (10). These cells display direct effector roles in the control of pathogen infections and cancer cells destruction, regulate the inflammatory response and modulate the adaptive immune cells. However, their role in cancer control is controversial, since they can also carry out roles whose final effect is to promote, rather than hinder, cancer growth (11).

These alternative functions reside in the ability of macrophages to display phenotypes endowed with specific functional roles, as exemplified by the two opposite polarization states (the M1-like anti-tumor and M2-like pro-tumor phenotypes, respectively) that macrophages can experience in response to different microenvironmental stimuli $(12,13)$. However, it has been recently established that macrophage polarization in several physiologic and pathologic conditions actually represents a continuum, in which these cells display a spectrum of distinct polarization states that do not fit to the oversimplified M1/M2 classification (14).

Reflecting their plasticity, within the tumor microenvironment (TME) macrophages acquiring distinct phenotypes and functions (resulting in the attenuation of their antitumor activity and induction of tumor-supporting functions) have been defined as tumor-associated macrophages (TAMs) with M2-like features. TAMs represent a mixed cell population with heterogeneous phenotypes and functions, which includes resident macrophages, infiltrating blood monocytes, and monocyte-related myeloid-derived suppressor cells, known to be involved in tumor initiation, growth, angiogenesis, metastasis, immunosuppression, cancer-related inflammation, and resistance to therapy (15).

Besides the widely acknowledged role of macrophages in the control of cancer growth in vivo, other components of the TME also strongly affect cancer progression, such as extracellular matrix (ECM) molecules, fibroblasts, endothelial cells, and other types of innate and adaptive immune cells (16).

Abbreviations: dNK, decidua-like Natural Killer cells; ECM, Extracellular Matrix; GWAS, Genome wide association studies; LPS, lipopolysaccharide; MM, Multiple Myeloma; MMSET, Multiple myeloma set domain; NK, Natural Killer cells; SNPs, Single nucleotide polymorphisms; TAMs, Tumor-associated macrophages; TME, Tumor microenvironment; TRAF2, Tumor necrosis factor receptor-associated factor 2 .
For instance, natural killer (NK) cells are known to be altered under hypoxic conditions (a typical stress condition experienced by cancer cells) by assuming a uterine/decidua-like NK (dNK) cell phenotype (17) which display low cytotoxicity and is involved in angiogenesis and blastocyst implantation (18-20). NK cells are effector lymphocytes of the innate immunity endowed with cytotoxic activity and Th1 cytokine production (17). However, in cancer patients NK cells display very low cytotoxicity $(21,22)$ and a pro-angiogenic phenotype (23-26).

The involvement of the innate immune system in the control of cancer growth thus entails a complex crosstalk between most of its cellular components, whose interplay is just beginning to be defined. In fact, escaping the immune surveillance is now widely accepted as the seventh hallmark of cancer (27) and a widely pursued task in current cancer research is aimed at "reinstructing" the immune system to restore or enhance its anti-cancer activity (13).

Elucidating the roles and mechanisms of action of the molecular effectors within the TME which impact on the balance between the pro- and anti-tumor roles of the innate immune system thus represents a key topic in current cancer research, since it may open new opportunities for therapeutic interventions. In this context, several members of the T2 ribonuclease enzyme family have recently emerged as potential key players in innate immunity-mediated cancer growth control, by acting as stress-response, "alarmin"-like tumor suppressor genes.

\section{T2 RIBONUCLEASES: AN EMERGING FAMILY OF EVOLUTIONARILY CONSERVED, HIGHLY PLEIOTROPIC PROTEINS}

Ribonucleases (RNases) represent RNA-processing or degrading enzymes found in almost all organisms. They participate in many key cellular functions, such as DNA replication, control of gene expression, extracellular signaling and host defense (28).

Being RNAs involved in key biological processes (29), proteins affecting RNA turnover have been thoroughly investigated to better understand their role in basic cellular processes, such as cell proliferation, differentiation, apoptosis, and migration. Of note, dysregulation of these biological processes are known to be involved in cancer development.

Among ribonucleases that hydrolyze single-stranded RNA (30), transferase-type represent an important subclass, epitomized by the extensively investigated RNase A protein family (31). A key feature of these enzymes is their secretion in the extracellular milieu or their localization in several subcellular structures. Despite these ribonucleases have been classified in several ways, in broad terms they are classified as alkaline ribonucleases (T1 and A families) and acid ribonucleases (T2 family) (32).

T2 ribonucleases were originally classified by their similarity to the first acid ribonuclease purified from Aspergillus oryzae (33). T2 ribonucleases can be distinguished from A and T1 family members based on their preferential acidic $\mathrm{pH}$ for optimal 
catalytic activity and their impressively wide evolutionary conservation (unlike $\mathrm{T} 1$ and $\mathrm{A}$ ribonucleases, T2 ribonucleases have been widely reported among taxa) (Figure 1A) (36). Such striking pattern of evolutionary conservation suggests a very ancient and key role for this class of ribonucleases. All members of the T2 ribonucleases family are also characterized by two characteristic catalytic sites (CAS) I and II motifs, endowed with the catalytic function (Figure 1B).

The extremely wide evolutionary conservation of T2 ribonucleases is coupled to their involvement in several physiological functions, ranging from scavenging phosphate for nutritional needs to neural development, prevention of self-pollination in plants, cell cytotoxicity, modulation of the cytoskeleton, angiogenesis, and stress response (36).

Noteworthy, many of these biological processes are implicated in cancer development. For instance, the T2 ribonucleases from Aspergillus niger has been reported to display both anticarcinogenic and antiangiogenic properties $(37,38)$.

Moreover, like several vertebrate ribonucleases A family members (39), T2 ribonucleases from different species have been recently reported to be involved in immune response modulation, another biological process tightly linked to cancer growth control. For instance, the RNASET2 protein secreted by the parasite Schistosoma mansonii has been reported to prime host dendritic cells to trigger a Th2 polarization of $\mathrm{CD}^{+}{ }^{+} \mathrm{T}$ lymphocytes during infection (40-42), although the reported effect of the Schistosoma T2 RNase on the host innate immune response was different from that later described in mammalian experimental models, being dendritic cells rather than macrophages the main target of the protein. This apparently different roles of $\mathrm{T} 2$ ribonuclease family members might reflect the evolutionary distant experimental models used (i.e., a trematode parasite and mammalian species).

Moreover, transcriptional profiling of human MEC-1 cells-derived leukemic tumors developing in vivo in a murine experimental model where host macrophages were depleted showed a marked downregulation of human RNASET2 expression in actively growing tumors only (43). The last report suggested an oncosuppressive role for human RNASET2 mediated by the involvement of the host innate immune system.

\section{HUMAN RNASET2: AN ALARMIN-LIKE TUMOR SUPPRESSOR GENE ACTING ON CELLS FROM THE MONOCYTE/MACROPHAGE LINEAGE}

The RNASET2 gene represents the only human member of the T2 extracellular ribonucleases family and has been mapped on human $6 \mathrm{q} 27$, a region which has been frequently found to be rearranged in a wide range of cancers (44-50). The RNASET2 protein includes 256 aminoacid residues, encoding a signal peptide at the N-terminal and the two canonical I/II catalytic sites (Figure 1B) (34). A putative Tumor necrosis factor Receptor-Associated Factor-2 (TRAF-2) binding site was also predicted in the C-terminal part and has been suggested to play a role in RNASET2-mediated apoptosis in both human melanocytes and keratinocytes (35). T2 ribonucleases are normally extracellular proteins, but intracellular isoforms (34) have also been detected in the secretory pathway, lysosomes, mitochondria and processing bodies, cytoplasmic ribonucleoprotein (RNP) granules primarily composed of translationally repressed mRNAs and proteins related to mRNA decay (51-53).

Being localized in a chromosomal region that represents a common target for rearrangements in a wide spectrum of cancer types, the putative role of RNASET2 as a tumor suppressor gene has long been investigated.

Our group initially chose human ovarian carcinoma as an experimental model to test the role of RNASET2 as a tumor suppressor gene. Indeed, this gene shows an expression pattern which is compatible with a role in ovarian cancer, being expressed in ovarian and fallopian tube surface epithelia, the structures from which most ovarian carcinomas are thought to arise (54). Interestingly, we showed the RNASET2 gene to be frequently downregulated in both ovarian cancer-derived cell lines and tumor samples (55).

To better define the function of RNASET2, both ovarian carcinoma and malignant melanoma-derived human cell lines were used for in vivo xenograft assays carried out in nude mice. Strikingly, RNASET2-overexpressing clones derived from both cell lines displayed a marked suppression of their tumorigenic potential in vivo $(56,57)$.

Tumors derived from human cancer cells overexpressing a catalytically inactive RNASET2 protein were equally suppressed in their in vivo growth rate when compared to their wildtype RNASET2-expressing counterpart, suggesting that RNASET2-mediated tumor suppression is independent from its ribonuclease activity (57). The latter was not a completely unexpected finding, since other members of the $\mathrm{T} 2$ ribonuclease family are known to carry out a particular biological process independently of their catalytic activity (36).

A detailed histological survey showed that xenograft-derived suppressed tumors overexpressing RNASET2 were strongly infiltrated by murine stromal cells belonging to the M1 subclass of macrophages, which are known to display a marked antitumorigenic role (57). These data were confirmed by a further in vivo xenograft-based assay, where in vivo depletion of host macrophages largely restored the tumorigenic potential of RNASET2-overexpressing human ovarian cancer cells (57). These data strongly pointed at the monocyte/macrophage cell lineage as a key component of RNASET2-mediated tumor suppression.

The crucial role of host macrophages was confirmed in an independent xenograft-based model, whereby knock-down of endogenously expressed RNASET2 in human OVCAR3 ovarian cancer cells was associated with a marked increase in their growth rate in vivo, coupled with a significant decrease of M1-polarized macrophage infiltration (58). Moreover, gene expression analysis in two human cancer types (ovarian cancer and chronic lymphocytic leukemia) unveiled a gradual decrease of RNASET2 gene expression with increasing stage or grade (which is an expected pattern for an oncosuppressor gene) (59). However, both cancer types, actually showed a marked upregulation of 
A

\begin{tabular}{|c|c|}
\hline Saccharomyces & MLLKNLHSLLQLPIF SNGADKGIEPNCPINIPLSCSNKTDIDNSCCFEYPGGIFLQTQFW \\
\hline Hirudo & 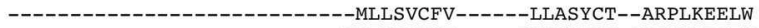 \\
\hline Danio & ----MRF IAFAVI-----FSAVYLCS-SAFTHPRGEW \\
\hline Homo & $-------0-$ MRPAALRGALLGCL-----CLA-------LLCLGGADKRLRDNHEW \\
\hline Macaca & $-------0---$ MRPAALRGALLGCL-----YLA-------LLCLGGADKRLRDNHEW \\
\hline Rattus & -----------MAEARGALPGWVSVLGWGLA-------LCCLCGAGPLWSGSHEW \\
\hline Mus & $---1-1-1$ MAPAEARGALPGWISVLGWGLA------LCSLCGAGPLWSGSHEW \\
\hline
\end{tabular}

Saccharomyces NYFPSKND---------LNETELVKELGPLDSFTIHGLWPDNCHGGYQQFCNRSLQIDD Hirudo

Danio

Homo

Macaca

Rattus

Mus

Saccharomyces

Hirudo

Danio

Homo

Macaca

Rattus

Mus

Saccharomyces

Hirudo

Danio

Homo

Macaca

Rattus

Mus

Saccharomyces

Hirudo

Danio

Homo

Macaca

Rattus

Mus

Saccharomyces

Hirudo

Danio

Homo

Macaca

Macaca

Rattus
Mus

Saccharomyces

Hirudo

Danio

Homo

Macaca

Rattus

Mus

Saccharomyces

Hirudo

Danio

Danio
Homo

Macaca

Rattus

Mus
DHFVFTQEWPQSICWELDYTEEEECMLPEKTNFWTIH HLWP SYONTRGPNFCTKD---TKLILTQHWPQTFCKM--E----HC--KTDFSYWTI HGLWPNTGVR----CNTSW----KKLIMVQHWPETVCEKION----DC--RDPPDYWTIH GLWPDKSEG----CNRSW----KKLIMVOHWPETVCEKION----DC--RDPPDYWT I H GLWPDKSEG----CNRSW----KKLILTQHWPPTVCKEV-N----RC--RDSLDYWT IH GLWPDRAED----CNHSW-----KKLILTQHWPPTVCKEV-N----SC--QDSLDYWT I H GLWPDRAED----CNQSW----: : :

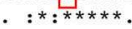

VYYLLHDKKFNNNDTSLQISGEKLLEYLDLYWKS---NNGNHESLWIHEFNKHGTCISTI -------KFNES------LI SPLEDOLI INWPNLK-PNTGKYSFWKHEWDKHGTCALS------HFNAS------LIEDILPEMEKFWPDLLEP--SSPKFWNYEWTKHGTCAAK----- PFNLE------EIKDLLPEMRAYWPDVIHSFPNRSRFWKHEWEK HGTCAAQ--------PFNLE------EI KDLLPEMRAYWPDVIHSFPNRSRFWKHEWEKH GTCAAQ-------HFNLN------EI KDLLRDMK IYWPDVI HP S SNRSOFWKHEWDKH GTCAAQ--------HFNLD------EIKDLLRDMK IYWPDVIHRS SNRSOFWKHEWVKHGTCAAQ-

$$
\text { **. }
$$

RPECYTEWGANSVDRKRAVYDYFRITYNLFKKLDTFSTLEKNNIVPSVDNSYSLEOIEAA ------MDELDSELKYFKKVLELHKTFDVMKGLKEAGF GP SDKDSYQYEDLDAA -------SESLNSEHKYFGKALELYHKFDLNSVLLKNQIVPSE-KHYTLEDVEEA --_--_---VDALNSQKKYFGRSLELYRELDLNSVLLKLGIKPSI-NYYQVADFKDA --------VDALNSQKKYFGRSLELYRELDLNSVLLKLGIKPSI-NYYQVADFKDA ---------VDALNSERKYFGKSLDLYKOIDLNSVLOKFEIKPSI-NYYOLADFKDA DALNSEKKYFGKSLDLYKQIDLNSVLOKFGIKPSI-NYYOLADFKDA

LSKEFEGKKVFIGCDRHNSLNEVWYYNHLKGSLLSEMFVPMDSLAIRTNCKKDGIKFFPK LESVLGV-KGMIMCYNPR-NEPIOYLAOIEFCLDK-SFOPM------OCPHHSYEASLE ITSAYGV-KPKIQCVHPGQGGQVQILGQIEICVDR-DFQLM-------GCEKSSEDTWSN ITSAYGV-KPKIQCVHPGQGGQVQI LGQIEICVDR-DFQLM-------GCEKSSEDTWSN
LARVYGV-IPKIQCLPPSODEEVQTIGQIELCLTKODQQLQ------NCTEPGEQPSPK LARVYGV-IPKIQCLPPSQDEEVQTVGQIELCLTKQDQQLQ-------NCTEPGEQLSPK LTRIYGV-VPKIQCLMPEQGENVQT IGQIELCFTKEDFHLR--------NCTEPEEQPSSC LTRIYGV-VPKIQCLMPEQGESVQTVGQIELCFTKEDLHLR-------NCTEPGEOLSSR$$
* *
$$$$
\text { : : : : . . }
$$$$
\text { *. . }
$$

GYVPPFRRRPN---------KGARYRGV--VRLSNINNGDOMOG-------FLIKN--GHWM NPDQSLHRISDFESTVLESKERNLHQVLKMR I HNKNNTNTFTGRSQSQEFKMRELRINIC

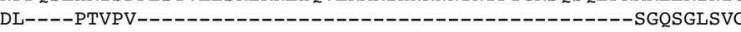

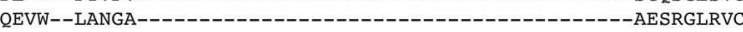

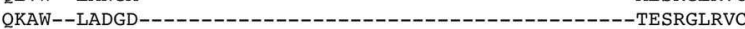

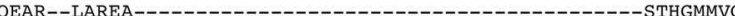

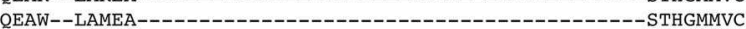

SQGTPANYELIKSPYGNYYLRTNQGFCDIISSSSNELVCKFRNIKDAGQFDFDPTKGGDG SDKKE IMYPI IDHNQMNQ---------IHSNS---------------DHSMPVYYPPVQA-------

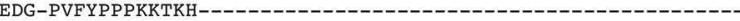
EDG-PVFYPPPKKIKH---

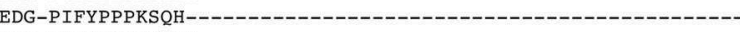

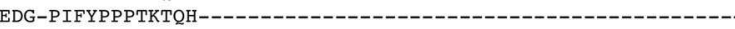
.. *

YIGYSGNYNWGGDTYPRRRNQSPIFSVDDEQNSKKYKFKLKFIKN

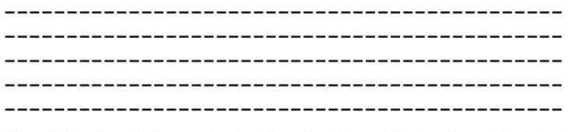

B

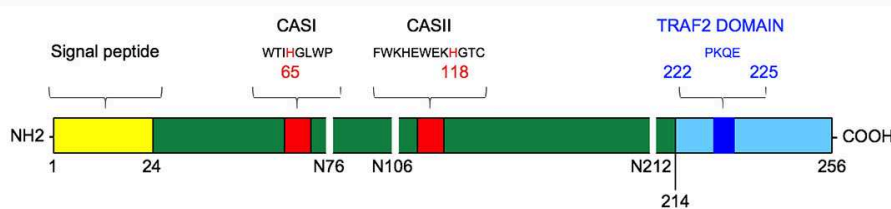

FIGURE 1 | Structural features and evolutionary conservation of T2 RNase proteins. (A) A Clustal Omega alignment of several members of the T2 RNase family, showing the wide evolutionary conservation of this enzymes. RNA cleavage by T2 RNases is mediated by histidine residues (red boxes) embedded into two highly conserved motifs dubbed CAS I and CAS II. The species included in the alignment are Saccharomices cerevisiae, Hirudo verbana, Danio rerio, Homo sapiens, 
FIGURE 1 | Macaca mulatta, Rattus norvegicus, and Mus musculus. (B) Structure of human RNASET2. The RNASET2 primary sequence includes 256 aminoacid residues, with a predicted molecular weight of about $30 \mathrm{kDa}$. The core enzyme is colored in dark green in the figure. Among the protein's structural features, a 24-residues long signal peptide for secretion at the N-terminal (yellow bar) and the two canonical CAS sites (CAS I/II, red bars) responsible for the enzyme's catalytic activity (bearing a highly conserved key histidine residue at position 65 and 118, respectively) are shown in the figure. Three N-glycosylation sites (white horizontal lines), which increase the molecular weight of the native protein of about $6 \mathrm{kDa}$, are also shown (34). Finally, a putative TRAF-2 binding site (dark blue bar) was predicted in the C-terminal part of RNASET2 (light blue bar, starting form residue 214), which is less evolutionary conserved throughout evolution and has been suggested to be comprise a highly disordered loop (35). Within the cell, the RNASET2 protein is present in three forms of different sizes, namely 36,31 , and $27 \mathrm{kDa}$ (34). The $36 \mathrm{kDa}$ isoform represents the full-length and secreted form, which is easily detected in cell culture supernatants from RNASET2-expressing cells, whereas the other two isoforms represent intracellular protein isoforms originating from proteolytic cleavage of the full-length protein (B).

RNASET2 expression at early stages when compared to the healthy tissue, followed by a gradual decrease in advanced stages.

These data strongly pointed at a non-cell autonomous oncosuppressive role of RNASET2, by which cancer cells secreting high levels of this protein might send a sort of "alarm" message to monocytes/macrophages in order to promote their oncosuppressive activity by means of their active recruitment, activation, and polarization (Figure 2). According to this hypothesis, RNASET2 might represent a novel member of the “alarmin" family, molecules passively released by necrotic cells or actively secreted by epithelial or immune cells in order to signal to the innate immune system the occurrence of dangerous events $(60,61)$.

In keeping with the alarmin hypothesis, overexpression in human ovarian cancer cells of an engineered RNASET2 protein bearing an endoplasmic reticulum retention signal (to prevent protein secretion) largely restored the ability of these cells to form fast-growing tumors in vivo, thus demonstrating the key role of extracellular RNASET2 in tumor suppression (62). A role in innate immune system modulation has been reported for other extracellular ribonucleases, such as some human ribonuclease A family members (39) and, significantly, a T2 ribonuclease secreted by the Schistosoma mansonii parasite's eggs during mammalian infection $(40,41)$.

Furthermore, alarmins are known to work as stress response proteins and, accordingly, several members of the $\mathrm{T} 2$ ribonuclease family are known to act as stress response genes in several species $(51,62-64)$.

As long as human RNASET2 is concerned, its expression and extracellular secretion are markedly increased both in vitro and in vivo under a wide range of stressful conditions $(35,62,65,66)$, among which hypoxia and nutritional starvation, two stressful conditions typically experienced by early-stage cancer cells.

Gene expression analysis based on publicly available datasets indicates that RNASET2 is also expressed in Multiple Myeloma (MM) cells (http://www.humanmine.org-RNASET2). Interestingly, although expression levels RNASET2 in MM patients does not change much from its precancerous Monoclonal Gammopathy of Undetermined Significance stage, recent evidence suggest that this gene is significantly regulated by epigenetic modifications, as observed in $t_{(4 ; 14)^{+}}$ myeloma cells overexpressing the histone methyltransferase MMSET, a driving factor in the pathogenesis of this subtype of myeloma.

Investigations of the T2 ribonuclease from Aspegillus niger (ACTIBIND) based on xenograft models have confirmed the strong, non cell-autonomous in vivo tumor suppressive activity for this class of proteins $(37,38)$.

The functional nature of the crosstalk between RNASET2 and cells from the monocyte/macrophage lineage was also recently investigated. Strikingly, human recombinant RNASET2 was shown to act as a potent chemokine for cells belonging to the monocyte/macrophage lineage (58), in keeping with the previous in vivo data $(57,58)$.

Furthermore, knock-down of endogenous RNASET2 expression in the human promonocytic THP1 cell line model was shown to affect the polarization pattern of differentiated THP-1-derived macrophages by promoting a shift form the antitumor M1 to the pro-tumor M2 state (67). These data provide a further support to the previously reported recruitment of M1-polarized macrophages in RNASET2-overexpressing tumor xenografts and point at RNASET2 as an alarmin-like molecule.

Given the extreme evolutionary conservation of T2 ribonucleases, their role as innate immune system modulators has been recently investigated in non-vertebrate experimental models. Strikingly, recombinant RNASET2 injection in the body wall of the invertebrate medicinal leech Hirudo verbana triggered a massive recruitment of $\mathrm{AIF}^{+}{ }^{+}$host macrophages into the injected area, again supporting the role of RNASET2 as a chemoattractant molecule for monocyte/macrophages (68).

The recruited macrophages were shown to be functionally activated as phagocytic cells and to actively express their endogenous RNASET2 gene, suggesting the occurrence of a putative RNASET2-mediated positive feedback in these cells (68). The confirmation of a functional crosstalk between a T2 ribonuclease and tissue macrophages in evolutionarily distant taxa is of key relevance, since it suggests a very ancient and conserved role for $\mathrm{T} 2$ ribonucleases in host defense.

\section{IS THE CROSSTALK BETWEEN HUMAN RNASET2 AND THE IMMUNE SYSTEM WIDER THAN EXPECTED? HINTS FROM RECENT EXPERIMENTAL DATA}

In recent years, further investigations led to the discovery of the molecular pathways by which $\mathrm{T} 2$ ribonuclease family members carry out their oncosuppressive role. Therefore, depending on the adopted experimental system, T2 ribonucleases have been reported to control key cellular processes such as angiogenesis, apoptosis, cytoskeletal rearrangements, cell invasion, and innate immune cells activation or polarization $(35,38,62,63,67$, 

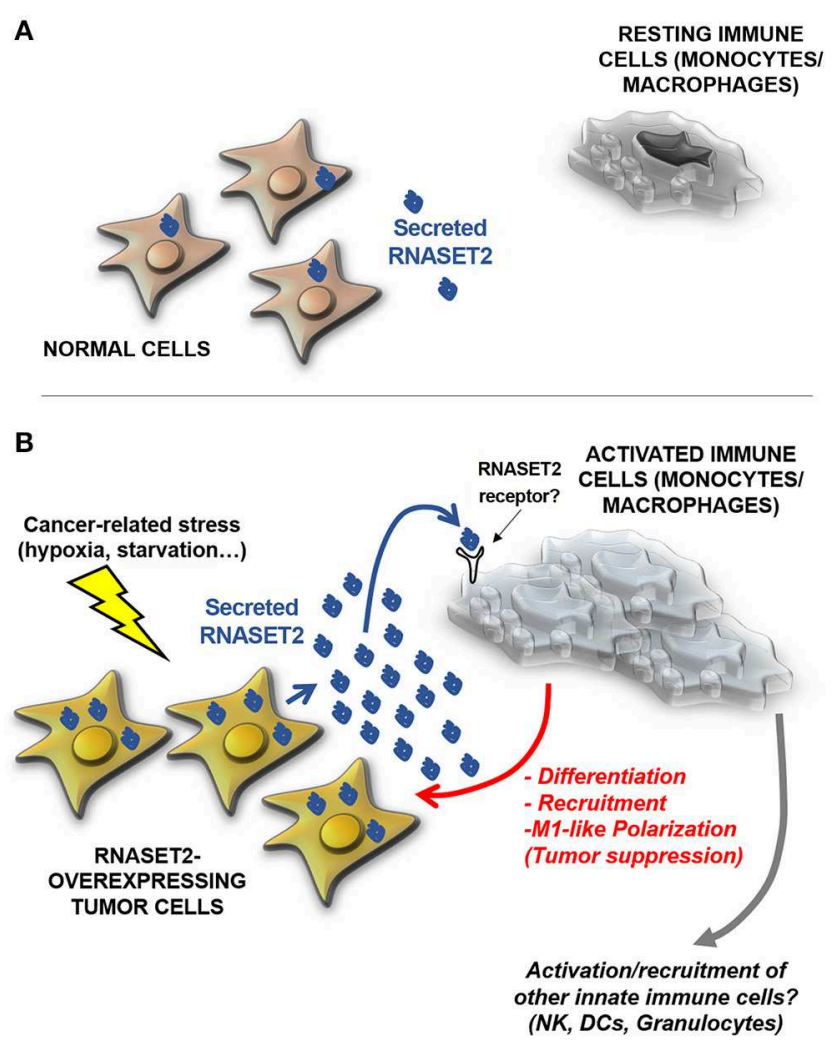

FIGURE 2 | A model for human RNASET2-mediated tumor suppression. (A) In physiological contexts, most human cells express low or undetectable RNASET2 levels (https://www.ncbi.nlm.nih.gov/gene/8635), with the notable exception of spleen, lymph nodes and colon, three tissues highly involved in immune system function. This ubiquitous "baseline" RNASET2 expression can be related to the execution of intracellular or extracellular roles (some yet-to-be defined) possibly mediated by its catalytic activity. (B) When cells are locally exposed to a wide range of stresses, some of which are typically experienced by cancer cells (such as hypoxia, oxidative stress or nutritional starvation), they activate a "danger-response" program which involves, besides the activation of several endogenous stress response pathways, a massive increase in expression and secretion of RNASET2, which acts as an alarmin-like molecule to engage cells belonging to the innate immune system (mostly macrophages, but possibly other cellular components such as natural killer (NKs), dendritic cells (DCs) and granulocytes) to coordinate an immune-response-mediated tumor suppressive response. As previously described for several biological processes mediated by T2 RNases, the catalytic activity of the RNASET2 is not required to trigger this marked immune system-mediated response. Strikingly, the functional crosstalk between RNASET2 and cellular effectors of the innate immune system has been reported in several evolutionary distant species, suggesting an ancient key role of T2 RNases in immune-response mediated host defense.

69). Based on these data, T2 ribonucleases are currently considered highly pleiotropic proteins endowed with an ancient, evolutionary conserved role related to stress response and host defense.

In this context, granulocytes represent further key effector cells of the innate immune system. Strikingly, our recent investigations in the medicinal leech showed endogenous RNASET2 overexpression in these cells following lipopolysaccharide injection into the body wall (70) and the RNASET2 protein was detected in the granules of these cells, suggesting a further role in innate immunity-mediated host defense.

Taken together, these data make RNASET2 a strong candidate gene for innate immune response-mediated control of cancer growth, by means of a complex multicellular network involving other cells besides tissue macrophages.

Finally, a new piece in the puzzle has been recently added by the results of several genome-wide association studies (GWAS), where a few SNPs nearby the RNASET2 gene have been strongly associated with the risk for several human autoimmune diseases, such as Grave's disease, vitiligo, Crohn's disease, rheumatoid arthritis, and type I diabetes (71-75). Some of these polymorphisms were shown to modulate RNASET2 expression (76), again suggesting a key a role for RNASET2 in host immune response regulation.

Given the known functional link between autoimmune disease and cells from the innate immune systems (77), these recent observations further support a pleiotropic and widespread role for $\mathrm{T} 2$ ribonucleases in immune system-mediated host defense mechanisms.

\section{CONCLUSION}

The RNASET2 gene is the only human member of this extracellular ribonuclease gene family. Unlike other ribonucleases, T2 ribonucleases have been discovered in most organisms and are mostly related to stress response and host defense. Significantly, the roles assigned to T2 ribonucleases are often mediated by biological processes tightly linked to cancer development (36).

Despite some of these processes apparently suggest a cell-autonomous oncosuppressor role for T2 ribonucleases, recent experimental data point at the occurrence of a functional crosstalk between members of this extracellular protein family and the tumor microenvironment as well.

Interestingly, establishing this crosstalk represents a key step in T2 ribonuclease-mediated tumor suppression in some in vivo experimental models. In particular, T2 ribonucleases from evolutionary distant species such as Homo sapiens, Schistosoma mansonii and Hirudo verbana all share a common ability to functionally interact with and modulate one or more cellular effectors of the innate immune system. These data suggest that modulation of the immune system by $\mathrm{T} 2$ ribonucleases represent a very ancient feature aimed at coordinating an effective host defense response.

Beside this, in light of the growing attention for anticancer immunotherapy approaches (78), RNASET2mediated regulation of the immune system might suggest an innovative approach in clinical oncology, based on the use of recombinant RNASET2 protein as a wide-range, pleiotropically acting antitumor drug, acting to fight cancer cells at both cell-autonomous, and non cell-autonomous levels.

Finally, the recent results from a number of GWAS, pointing at human RNASET2 gene polymorphisms as a risk factor for several autoimmune diseases, add further support to the notion of a complex and widespread involvement of this protein in 
immune system modulation, by indicating at the same time a novel target for drug development for this group of devastating human diseases.

\section{AUTHOR CONTRIBUTIONS}

FA, LM, AD, DB, AA, MC, RT, and DN contributed to this work by planning, organizing, writing, revising, and assembling the manuscript and by preparing the figures.

\section{REFERENCES}

1. Buchmann K. Evolution of innate immunity: clues from invertebrates via fish to mammals. Front Immunol. (2014) 5:459. doi: 10.3389/fimmu.2014.00459

2. Mantovani A, Biswas SK, Galdiero MR, Sica A, Locati M. Macrophage plasticity and polarization in tissue repair and remodelling. J Pathol. (2013) 229:176-85. doi: 10.1002/path.4133

3. Kim R, Emi M, Tanabe K. Cancer immunosuppression and autoimmune disease: beyond immunosuppressive networks for tumour immunity. Immunology. (2006) 119:254-64. doi: 10.1111/j.1365-2567.2006.02430.x

4. Albini A, Bruno A, Noonan DM, Mortara L. Contribution to tumor angiogenesis from innate immune cells within the tumor microenvironment: implications for immunotherapy. Front Immunol. (2018) 9:527. doi: 10.3389/fimmu.2018.00527

5. Jones EY, Fugger L, Strominger JL, Siebold C. MHC class II proteins and disease: a structural perspective. Nat Rev Immunol. (2006) 6:271-82. doi: $10.1038 /$ nri1805

6. Raphael I, Nalawade S, Eagar TN, Forsthuber TG. T cell subsets and their signature cytokines in autoimmune and inflammatory diseases. Cytokine. (2015) 74:5-17. doi: 10.1016/j.cyto.2014.09.011

7. Rabinovich GA, Gabrilovich D, Sotomayor EM. Immunosuppressive strategies that are mediated by tumor cells. Annu Rev Immunol. (2007) 25:267-96. doi: 10.1146/annurev.immunol.25.022106.141609

8. Paluch C, Santos AM, Anzilotti C, Cornall RJ, Davis SJ. Immune checkpoints as therapeutic targets in autoimmunity. Front Immunol. (2018) 9:2306. doi: 10.3389/fimmu.2018.02306

9. Pardoll DM. The blockade of immune checkpoints in cancer immunotherapy. Nat Rev Cancer. (2012) 12:252-64. doi: 10.1038/nrc3239

10. Bruno A, Pagani A, Pulze L, Albini A, Dallaglio K, Noonan DM, et al. Orchestration of angiogenesis by immune cells. Front Oncol. (2014) 4:131. doi: 10.3389/fonc.2014.00131

11. Noonan DM, De Lerma Barbaro A, Vannini N, Mortara L, Albini A. Inflammation, inflammatory cells and angiogenesis: decisions and indecisions. Cancer Metastasis Rev. (2008) 27:31-40. doi: 10.1007/s10555-007-9108-5

12. Mills CD, Kincaid K, Alt JM, Heilman MJ, Hill AM. M-1/M-2 macrophages and the Th1/Th2 paradigm. J Immunol. (2000) 164:6166-73. doi: 10.4049/jimmunol.164.12.6166

13. Mantovani A, Marchesi F, Malesci A, Laghi L, Allavena P. Tumour-associated macrophages as treatment targets in oncology. Nat Rev Clin Oncol. (2017) 14:399-416. doi: 10.1038/nrclinonc.2016.217

14. Murray PJ, Allen JE, Biswas SK, Fisher EA, Gilroy DW, Goerdt S, et al. Macrophage activation and polarization: nomenclature and experimental guidelines. Immunity. (2014) 41:14-20. doi: 10.1016/j.immuni.2014.06.008

15. Parisi L, Gini E, Baci D, Tremolati M, Fanuli M, Bassani B, et al. Macrophage polarization in chronic inflammatory diseases: killers or builders? J Immunol Res. (2018) 2018:1-25. doi: 10.1155/2018/8917804

16. Chen F, Zhuang X, Lin L, Yu P, Wang Y, Shi Y, et al. New horizons in tumor microenvironment biology: challenges and opportunities. BMC Med. (2015) 13:45. doi: 10.1186/s12916-015-0278-7

17. Cerdeira AS, Rajakumar A, Royle CM, Lo A, Husain Z, Thadhani RI, et al. Conversion of peripheral blood NK cells to a decidual NK-like

\section{FUNDING}

This work was supported by the University of Insubria intramural grant FAR 2018 and the Associazione Amici dell'Insubria to FA, the grant FAR 2018 and the MIUR National Fund for Basic Research grant FFABR 2017 to LM, the Sapienza University of Rome-Progetti Ateneo 2018 to MC, and the Italian Ministry of University and Research PRIN 2017 grant 2017NTK4HY to FA, LM, MC, and DN. DB was supported by a senior Insubria’s postdoctoral grant sponsored by MIUR.

phenotype by a cocktail of defined factors. J Immunol. (2013) 190:3939-48. doi: 10.4049/jimmunol.1202582

18. Hanna J, Goldman-Wohl D, Hamani Y, Avraham I, Greenfield C, NatansonYaron S, et al. Decidual NK cells regulate key developmental processes at the human fetal-maternal interface. Nat Med. (2006) 12:1065-74. doi: $10.1038 / \mathrm{nm} 1452$

19. Le Bouteiller P, Tabiasco J. Killers become builders during pregnancy. Nat Med. (2006) 12:991-2. doi: 10.1038/nm0906-991

20. Santoni A, Carlino C, Stabile H, Gismondi A. Mechanisms underlying recruitment and accumulation of decidual $\mathrm{NK}$ cells in uterus during pregnancy. Am J Reprod Immunol. (2008) 59:417-24. doi: 10.1111/j.1600-0897.2008.00598.x

21. Vivier E, Tomasello E, Baratin M, Walzer T, Ugolini S. Functions of natural killer cells. Nat Immunol. (2008) 9:503-10. doi: 10.1038/ni1582

22. Bruno A, Ferlazzo G, Albini A, Noonan DM. A think tank of TINK/TANKs: Tumor-infiltrating/tumor-associated natural killer cells in tumor progression and angiogenesis. J Natl Cancer Inst. (2014) 106:dju200. doi: $10.1093 /$ jnci/dju200

23. Bosi A, Zanellato S, Bassani B, Albini A, Musco A, Cattoni M, et al. Natural killer cells from malignant pleural effusion are endowed with a decidual-like proangiogenic polarization. J Immunol Res. (2018) 2018:1-18. doi: $10.1155 / 2018 / 2438598$

24. Bruno A, Focaccetti C, Pagani A, Imperatori AS, Spagnoletti M, Rotolo N, et al. The proangiogenic phenotype of natural killer cells in patients with non-small cell lung cancer. Neoplasia. (2013) 15:133-42. doi: 10.1593/neo. 121758

25. Bruno A, Bassani B, D’Urso DG, Pitaku I, Cassinotti E, Pelosi G, et al Angiogenin and the MMP9-TIMP2 axis are up-regulated in proangiogenic, decidual NK-like cells from patients with colorectal cancer. FASEB J. (2018) 32:5365-77. doi: 10.1096/fj.201701103R

26. Bassani B, Baci D, Gallazzi M, Poggi A, Bruno A, Mortara L, et al. Natural killer cells as key players of tumor progression and angiogenesis: old and novel tools to divert their pro-tumor activities into potent anti-tumor effects. Cancers. (2019) 11:E461. doi: 10.3390/cancers11040461

27. Hanahan D, Weinberg RA. Hallmarks of cancer: the next generation. Cell. (2011) 144:646-74. doi: 10.1016/j.cell.2011.02.013

28. D’Alessio G, Riordan J. Ribonucleases: Structures and Functions. New York, NY: Academic Press (1997).

29. Gingeras TR. Origin of phenotypes: genes and transcripts. Genome Res. (2007) 17:682-90. doi: 10.1101/gr.6525007

30. D'Alessio G, Riordan J. Ribonucleases: Structures and Functions. New York, NY: Academic Press (1997).

31. Rosenberg HF. RNase A ribonucleases and host defense: an evolving story. $J$ Leukoc Biol. (2008) 83:1079-87. doi: 10.1189/jlb.1107725

32. Deshpande RA, Shankar V. Ribonucleases from T2 family. Crit Rev Microbiol. (2002) 28:79-122. doi: 10.1080/1040-840291046704

33. Sato K, Egami F. Studies on ribonucleases in takadiastase. I. J Biochem. (1957) 44:753-67. doi: 10.1093/oxfordjournals.jbchem.a126717

34. Campomenosi P, Salis S, Lindqvist C, Mariani D, Nordström T, Acquati F, et al. Characterization of RNASET2, the first human member of the Rh/T2/S family of glycoproteins. Arch Biochem Biophys. (2006) 449:17-26. doi: $10.1016 /$ j.abb.2006.02.022 
35. Wang Q, Jiang M, Wu J, Ma Y, Li T, Chen Q, et al. Stress-induced RNASET2 overexpression mediates melanocyte apoptosis via the TRAF2 pathway in vitro. Cell Death Dis. (2014) 5:e1022. doi: 10.1038/cddis.2013.539

36. Luhtala N, Parker R. T2 Family ribonucleasess: ancient enzymes with diverse roles. Trends Biochem Sci. (2010) 35:253-9. doi: 10.1016/j.tibs.2010.02.002

37. Roiz L, Smirnoff P, Bar-Eli M, Schwartz B, Shoseyov O. ACTIBIND, an actin-binding fungal T2-RNase with antiangiogenic and anticarcinogenic characteristics. Cancer. (2006) 106:2295-308. doi: 10.1002/cncr. 21878

38. Schwartz B, Shoseyov O, Melnikova VO, McCarty M, Leslie M, Roiz L, et al. ACTIBIND, a T2 RNase, competes with angiogenin and inhibits human melanoma growth, angiogenesis, and metastasis. Cancer Res. (2007) 67:525866. doi: 10.1158/0008-5472.CAN-07-0129

39. Lu L, Li J, Moussaoui M, Boix E. Immune modulation by human secreted RNases at the extracellular space. Front Immunol. (2018) 9:1012. doi: 10.3389/fimmu.2018.01012

40. Steinfelder S, Andersen JF, Cannons JL, Feng CG, Joshi M, Dwyer D, et al. The major component in schistosome eggs responsible for conditioning dendritic cells for Th2 polarization is a T2 ribonuclease (omega-1). J Exp Med. (2009) 206:1681-90. doi: 10.1084/jem.20082462

41. Everts B, Perona-Wright G, Smits HH, Hokke CH, van der Ham AJ, Fitzsimmons CM, et al. Omega-1, a glycoprotein secreted by Schistosoma mansoni eggs, drives Th2 responses. J Exp Med. (2009) 206:1673-80. doi: $10.1084 /$ jem. 20082460

42. Everts B, Hussaarts L, Driessen NN, Meevissen MHJ, Schramm G, van der Ham AJ, et al. Schistosome-derived omega-1 drives Th2 polarization by suppressing protein synthesis following internalization by the mannose receptor. J Exp Med. (2012) 209:1753-67, S1. doi: 10.1084/jem. 20111381

43. Galletti G, Scielzo C, Barbaglio F, Rodriguez TV, Riba M, Lazarevic D, et al. Targeting macrophages sensitizes chronic lymphocytic leukemia to apoptosis and inhibits disease progression. Cell Rep. (2016) 14:1748-60. doi: 10.1016/j.celrep.2016.01.042

44. Trent JM, Stanbridge EJ, McBride HL, Meese EU, Casey G, Araujo $\mathrm{DE}$, et al. Tumorigenicity in human melanoma cell lines controlled by introduction of human chromosome 6. Science. (1990) 247:568-71. doi: $10.1126 /$ science. 2300817

45. Cooke IE, Shelling AN, Le Meuth VG, Charnock FML, Ganesan TS. Allele loss on chromosome arm $6 \mathrm{q}$ and fine mapping of the region at $6 \mathrm{q} 27$ in epithelial ovarian cancer. Genes Chromosom Cancer. (1996) 15:223-33. doi: 10.1002/ (SICI)1098-2264(199604)15:4<223::AID-GCC4>3.0.CO;2-3

46. Tibiletti MG, Bernasconi B, Furlan D, Riva C, Trubia M, Buraggi G, et al. Early involvement of 6q in surface epithelial ovarian tumors. Cancer Res. (1996) 56:4493-8. doi: 10.1016/S0165-4608(97)82560-5

47. Gaidano G, Hauptschein R, Parsa N, Offit K, Rao P, Lenoir G, et al. Deletions involving two distinct regions of 6q in B-cell non-Hodgkin lymphoma. Blood. (1992) 80:1781-7. doi: 10.1182/blood.V80.7.1781.bloodjournal8071781

48. Steinemann D, Gesk S, Zhang Y, Harder L, Pilarsky C, Hinzmann B, et al. Identification of candidate tumor-suppressor genes in $6 \mathrm{q} 27$ by combined deletion mapping and electronic expression profiling in lymphoid neoplasms. Genes Chromosom Cancer. (2003) 37:421-6. doi: 10.1002/gcc. 10231

49. Li BCY, Chan WY, Li CYS, Chow C, Ng EKW, Chung SCS. Allelic loss of chromosome 6q in gastric carcinoma. Diagn Mol Pathol. (2003) 12:193-200. doi: 10.1097/00019606-200312000-00003

50. Negrini M, Sabbioni S, Possati L, Rattan S, Corallini A, Barbanti-Brodano $\mathrm{G}$, et al. Suppression of tumorigenicity of breast cancer cells by microcellmediated chromosome transfer: studies on chromosomes 6 and 11. Cancer Res. (1994) 54:1331-6.

51. Vidalino L, Monti L, Haase A, Moro A, Acquati F, Taramelli R, et al. Intracellular trafficking of RNASET2, a novel component of P-bodies. Biol Cell. (2012) 104:13-21. doi: 10.1111/boc.201100092

52. Haud N, Kara F, Diekmann S, Henneke M, Willer JR, Hillwig MS, et al. rnaset2 mutant zebrafish model familial cystic leukoencephalopathy and reveal a role for RNase T2 in degrading ribosomal RNA. Proc Natl Acad Sci USA. (2011) 108:1099-103. doi: 10.1073/pnas. 1009811107

53. Liu P, Huang J, Zheng Q, Xie L, Lu X, Jin J, et al. Mammalian mitochondrial RNAs are degraded in the mitochondrial intermembrane space by RNASET2. Protein Cell. (2017) 8:735-49. doi: 10.1007/s13238-0170448-9
54. George SHL, Garcia R, Slomovitz BM. Ovarian cancer: the fallopian tube as the site of origin and opportunities for prevention. Front Oncol. (2016) 6:108. doi: $10.3389 /$ fonc. 2016.00108

55. Acquati F, Morelli C, Cinquetti R, Bianchi MG, Porrini D, Varesco L, et al. Cloning and characterization of a senescence inducing and class II tumor suppressor gene in ovarian carcinoma at chromosome region 6q27. Oncogene. (2001) 20:980-8. doi: 10.1038/sj.onc. 1204178

56. Monti L, Rodolfo M, Lo Russo G, Noonan D, Acquati F, Taramelli R. RNASET2 as a tumor antagonizing gene in a melanoma cancer model. Oncol Res. (2008) 17:69-74. doi: 10.3727/096504008784523658

57. Acquati F, Bertilaccio S, Grimaldi A, Monti L, Cinquetti R, Bonetti P, et al. Microenvironmental control of malignancy exerted by RNASET2, a widely conserved extracellular RNase. Proc Natl Acad Sci USA. (2011) 108:1104-9. doi: $10.1073 /$ pnas. 1013746108

58. Acquati F, Lualdi M, Bertilaccio S, Monti L, Turconi G, Fabbri M, et al. Loss of function of ribonuclease $\mathrm{T} 2$, an ancient and phylogenetically conserved RNase, plays a crucial role in ovarian tumorigenesis. Proc Natl Acad Sci USA. (2013) 110:8140-5. doi: 10.1073/pnas.1222079110

59. Roggiani F, Riva C, Raspagliesi F, Porta G, Valli R, Taramelli R, et al. A cell-autonomous oncosuppressive role of human RNASET2 affecting ECM-mediated oncogenic signaling. Cancers. (2019) 11:E255. doi: $10.3390 /$ cancers 11020255

60. Coffelt SB, Scandurro AB. Tumors sound the alarmin(s). Cancer Res. (2008) 68:6482-5. doi: 10.1158/0008-5472.CAN-08-0044

61. Oppenheim JJ, Yang D. Alarmins: chemotactic activators of immune responses. Curr Opin Immunol. (2005) 17:359-65. doi: 10.1016/j.coi.2005.06.002

62. Lualdi M, Pedrini E, Rea K, Monti L, Scaldaferri D, Gariboldi M, et al. Pleiotropic modes of action in tumor cells of RNASET2, an evolutionary highly conserved extracellular RNase. Oncotarget. (2015) 6:7851-65. doi: 10.18632/oncotarget.3490

63. Thompson DM, Parker R. The RNase Rnylp cleaves tRNAs and promotes cell death during oxidative stress in Saccharomyces cerevisiae. J Cell Biol. (2009) 185:43-50. doi: 10.1083/jcb.200811119

64. Bariola PA, Howard CJ, Taylor CB, Verburg MT, Jaglan VD, Green PJ. The Arabidopsis ribonuclease gene RNS1 is tightly controlled in response to phosphate limitation. Plant J. (1994) 6:673-85. doi: 10.1046/j.1365-313X.1994.6050673.x

65. Caputa G, Zhao S, Criado AEG, Ory DS, Duncan JG, Schaffer JE. RNASET2 is required for ROS propagation during oxidative stressmediated cell death. Cell Death Differ. (2016) 23:347-57. doi: 10.1038/cdd. 2015.105

66. Uccella S, La Rosa S, Scaldaferri D, Monti L, Maragliano R, Sorrenti $\mathrm{E}$, et al. New insights into hypoxia-related mechanisms involved in different microvascular patterns of bronchopulmonary carcinoids and poorly differentiated neuroendocrine carcinomas. Role of ribonuclease T2 (RNASET2) and HIF-1 $\alpha$. Hum Pathol. (2018) 79:66-76. doi: 10.1016/j.humpath.2018.04.028

67. Scaldaferri D, Bosi A, Fabbri M, Pedrini E, Inforzato A, Valli R, et al. The human RNASET2 protein affects the polarization pattern of human macrophages in vitro. Immunol Lett. (2018) 203:102-11. doi: 10.1016/j.imlet.2018.09.005

68. Baranzini N, Pedrini E, Girardello R, Tettamanti G, de Eguileor M, Taramelli $\mathrm{R}$, et al. Human recombinant RNASET2-induced inflammatory response and connective tissue remodeling in the medicinal leech. Cell Tissue Res. (2017) 368:337-51. doi: 10.1007/s00441-016-2557-9

69. Smirnoff P, Roiz L, Angelkovitch B, Schwartz B, Shoseyov O. A recombinant human RNASET2 glycoprotein with antitumorigenic and antiangiogenic characteristics: Expression, purification, and characterization. Cancer. (2006) 107:2760-9. doi: 10.1002/cncr.22327

70. Baranzini N, Monti L, Vanotti M, Orlandi VT, Bolognese F, Scaldaferri $\mathrm{D}$, et al. AIF-1 and RNASET2 play complementary roles in the innate immune response of medicinal leech. J Innate Immun. (2019) 11:150-67. doi: $10.1159 / 000493804$

71. Chu X, Pan CM, Zhao SX, Liang J, Gao GQ, Zhang XM, et al. A genome-wide association study identifies two new risk loci for Graves' disease. Nat Genet. (2011) 43:897-901. doi: 10.1038/ng.898

72. Quan C, Ren YQ, Xiang LH, Sun LD, Xu AE, Gao XH, et al. Genome-wide association study for vitiligo identifies susceptibility loci at 6q27 and the MHC. Nat Genet. (2010) 42:614-8. doi: 10.1038/ng.603 
73. Gonsky R, Fleshner P, Deem RL, Biener-Ramanujan E, Li D, Potdar $\mathrm{AA}$, et al. Association of ribonuclease T2 gene polymorphisms with decreased expression and clinical characteristics of severity in crohn's disease. Gastroenterology. (2017) 153:219-32. doi: 10.1053/j.gastro.2017. 04.002

74. Zhu H, Xia W, Mo XB, Lin X, Qiu YH, Yi NJ, et al. Gene-based genomewide association analysis in European and Asian populations identified novel genes for rheumatoid arthritis. PLoS ONE. (2016) 11:e0167212. doi: 10.1371/journal.pone.0167212

75. Sharma A, Liu X, Hadley D, Hagopian W, Chen WM, Onengut-Gumuscu $\mathrm{S}$, et al. Identification of non-HLA genes associated with development of islet autoimmunity and type 1 diabetes in the prospective TEDDY cohort. $J$ Autoimmun. (2018) 89:90-100. doi: 10.1016/j.jaut.2017.12.008

76. Gabrielsen ISM, Amundsen SS, Helgeland H, Flåm ST, Hatinoor N, Holm K, et al. Genetic risk variants for autoimmune diseases that influence gene expression in thymus. Hum Mol Genet. (2016) 25:3117-24. doi: $10.1093 / \mathrm{hmg} / \mathrm{ddw} 152$
77. Shin J Il, Lee KH, Joo YH, Lee JM, Jeon J, Jung HJ, et al. Inflammasomes and autoimmune and rheumatic diseases: a comprehensive review. J Autoimmun. (2019) 103:102299. doi: 10.1016/j.jaut.2019.06.010

78. Dougan M, Dranoff G. Immune therapy for cancer. Annu Rev Immunol. (2009) 27:83-117. doi: 10.1146/annurev.immunol.021908.132544

Conflict of Interest: The authors declare that the research was conducted in the absence of any commercial or financial relationships that could be construed as a potential conflict of interest.

Copyright (C) 2019 Acquati, Mortara, De Vito, Baci, Albini, Cippitelli, Taramelli and Noonan. This is an open-access article distributed under the terms of the Creative Commons Attribution License (CC BY). The use, distribution or reproduction in other forums is permitted, provided the original author(s) and the copyright owner(s) are credited and that the original publication in this journal is cited, in accordance with accepted academic practice. No use, distribution or reproduction is permitted which does not comply with these terms. 